\title{
Acculturation Attitudes and Sociocultural Adaptation of Chinese Mainland Sojourners in Hong Kong
}

\author{
Yuanyi Ma \\ School of Foreign Languages, Guangdong Institute of Science and Technology \\ Jinwan District, Zhuhai, Guangdong Province, China \\ Faculty of Humanities, The Hong Kong Polytechnic University \\ E-mail: yuanyi.ma@connect.polyu.hk \\ Bo Wang (Corresponding author) \\ Centre for Translation Studies, The Hong Kong Polytechnic University \\ Hung Hom, Kowloon, Hong Kong \\ E-mail: bo.wang@connect.polyu.hk
}

Doi:10.7575/aiac.alls.v.6n.6p.69

Received: 28/06/2015

URL: http://dx.doi.org/10.7575/aiac.alls.v.6n.6p.69

Accepted: 03/09/2015

\begin{abstract}
Within these years, there has been a significant increase in the number of Chinese Mainland sojourners studying in Hong Kong. Due to the huge differences in various aspects like language, culture, cultural value, it would be considerably difficult for the Chinese Mainland students to adapt to the Hong Kong environment. This article investigates the ways for a group of doctoral students from Chinese Mainland to acculturate in Hong Kong. With the help of questionnaires, the difficulties that the sojourners have encountered in social situations are measured. It is found out that age and gender may have influenced the participants' acculturation strategies, and interpersonal relationship is that which the subjects have the most difficulties with, while academic domain is the area with the least difficulties. Meanwhile, the results have shown that competence of local language is not a determinant factor of the sociocultural adaptation, and female subjects seem to adapt better than male subjects.
\end{abstract}

Keywords: sojourner, acculturation, sociocultural adaptation, acculturation strategy

\section{Introduction}

There has been a significant increase in the number of Mainland student studying in the higher institutions of Hong Kong ever since the formulation of the policy that allows Mainland graduates from local higher institutions to work in Hong Kong (Guo, 2014). For example, as informed by the Academic Secretariat of the Hong Kong Polytechnic University, in the year of 2014, the number of Chinese Mainland students studying in the institution has reached 3,421 (excluding outpost and distance learning students), and 4,448 (including outpost and distance learning students). Considering the huge differences in language, culture, value system, life pace, etc., it would be a real challenge for Chinese Mainland students to fit into this new and unfamiliar culture. Therefore, this article aims to investigate the ways for Chinese Mainland students to acculturate in Hong Kong, and to measure sociocultural adaptation in terms of the difficulties the students have encountered in social situations.

\section{Literature Review}

\subsection{Studies on Acculturation Attitudes}

Acculturation is believed to occur "when two independent cultural groups come into continuous first-hand contact over an extended period of time" (Redfield, Linton, \& Herskovits, 1936, cited in Berry, Kim, Power, Young, \& Bujaki, 1989: 186). It is also defined as "the process of learning and acquiring the elements of the host culture" (Shibutani \& Kwan, 1965, cited in Wiseman, 1995:176).

During the process of acculturation, two major orientations of attitudes are found. One is to maintain and develop uniqueness of one's own culture, cultural identity and customs. The other is to recognize the value of intercultural contact and to seek positive relations with a much larger society. Based on these two major orientations, four acculturation attitudes are found, namely assimilation, integration, separation, and marginalization (Berry et al., 1989). To explain in simple terms, the four attitudes are all those adopted by different kind of people, assimilation by those who value intergroup relation but not cultural maintenance; integration by those who value both cultural maintenance and intergroup relations; separation by those who value cultural maintenance but not intergroup relations; while marginalization by those value neither intergroup relation nor cultural maintenance.

As mentioned above, Berry, et al. (1989) have classified acculturation attitudes into four major types and provided a detailed description of the design and validation of the culture-specific measurement of acculturation attitudes for French-Canadians, as well as Hungarian, Korean, and Portuguese immigrants in Canada. The design, validation and 
conduction of the Acculturation Attitude Statements (a questionnaire) are described in detail by Berry, et al. (1989). The construction of the acculturation attitude questionnaire generally involves forming an initial item pool, judging of representativeness of the items, phrasing positive and negatively, and finally forming an 80-item questionnaire measuring four orientation of acculturation attitudes. Although proved highly reliable, and valid, this questionnaire is far from perfect due to its ambiguous intergroup relation dimension, considerate length, heavy attendant demand and culture-specific design that is no easy for test construction (Ward \& Kennedy, 1994).

Following Berry et al.'s (1989) study, more researches (e.g. Searl \& Ward, 1990; Ward \& Kennedy, 1994; JasinskajaLahti \& Liebkind, 2000; Leung, 2001; Ataca \& Berry, 2002; Virta, Sam, \& Westin, 2004; Ouarasse, \& Vijver, 2005) are carried out to measure acculturation attitudes. Some studies (Ward \& Kennedy, 1994; Jasinskaja-Lahti \& Liebkind, 2000) construct questionnaires based on the model designed by Berry et al. (1989), which form two questions regarding each of the acculturation attitudes for targeted domains of life. One study (Ataca \& Berry, 2002) focuses on eleven attitude domains (friendship, lifestyle, social activity, food, holiday celebration, language use, decoration, newspaper readership, child-rearing style, children's values, children's moving out); while two other studies (Virta, Sam, \& Westin, 2004; Jasinskaja-Lahti \& Liebkind, 2000) focus on five domains (marriage, cultural traditions, language, social activities, and friends). Meanwhile, there are also some studies that are only targeted at either co-national (Leung, 2001) or host-national identification (Ouarasse, \& Vijver, 2005).

Some factors are found related to acculturation attitudes. For example, gender may be significantly related to acculturation attitudes. Length of residence is positively related to the identification of host-culture, and negatively related to ethnic culture. Also, higher education level may boost host culture identification. At the same time, age is reported to be significantly but inconsistently related to acculturation attitude (Ouarasse, \& Vijver, 2005).

The present study uses the Acculturation Index designed by Ward \& Kennedy (1994), which measures both co-national identity and host-national identity. Another advantage of the index is that, coupled with median split technique, it can classify subjects into four acculturation domains (Ward \& Kennedy, 1994).

\subsection{Studies on Sociocultural Adaptation}

The concepts of Psychological Adaptation and Sociocultural Adaptation (henceforth PA and SA respectively) are two major dimensions of the acculturation process. PA refers to "the feelings of well-being and satisfaction", while SA is related to the "ability to "fit in"" (Searle \& Ward, 1990: 450), "to acquire culturally appropriate skills" (Ward \& Kennedy, 1999), or "negotiate in interactive aspects of the new culture" (Searle \& Ward, 1990: 450). SA has been repeatedly measured in studies like Searle and Ward (1990), Ward and Kennedy (1994), Klemens and Bikos (2000), Ataca and Berry (2002), Brisset, Safdar, Lewis and Sabatier (2010), and Sochos and Diniz (2012).

The measurement of SA, also the one adopted in current study is the Sociocultural Adaptation Scale (SCAS) (Ward \& Kennedy, 1999), which is a "behavioral and cognitive measure that explores how an individual adjusts to a society in terms of cultural learning and functional social skills" (Klemens \& Bikos, 2000: 726). Its original version was in the form of a 16-item questionnaire developed in the 1990s that has been first used to measure cross-cultural SA of Malaysian and Singaporean students in New Zealand (Searle \& Ward, 1990). While in Klemens and Bikos (2000), several adaptations and revisions are done to "include items based on the host country studied" and to "provide overall improvement to the measure" (ibid: 726).

Similar to Furnham and Bochnner's (1982) Social Situations Questionnaire (SSQ) (Furnham \& Bochner, 1982), SCAS requires respondents to rate the amount of difficulties encountered in a certain situation with a five-point scale (i.e. no difficulty / slight difficulty / moderate difficulty / great difficulty / extreme difficulty). One difference between SSQ and SCAS is that "difficulty is not explicitly framed in affective terms relating to anxiety, discomfort, and embarrassment" (Ward \& Kennedy, 1999: 662). An advantage of the SCAS lies in its flexibility and modifiability to suit the need of different sojourner samples. The 1999 version of SCAS contains 40 items, but most versions contain 20-23 items, while most of the items are applicable to different sojourner groups (Ward \& Kennedy, 1999).

\subsection{Chinese Sojourners in Other Cultures}

Sojourners are defined as those who "live in another culture for a period of time, with the initial, continuous intention of returning to their native land" (Dion \& Dion, 1996:457). Since sojourner students are generally under the pressure of adapting to the different culture and the demanding student life, researches have thus usually been focused on sojourner adjustment and stress faced by sojourner students.

Dion and Dion (1989) have conducted a review of various researches that have explored the factors that lead to adaptation difficulties for Chinese sojourners in other cultures. Studies examined in Dion and Dion (1989) include Graham (1983), Dion and Toner (1988), Chataway and Berry (1989), Pak, Dion and Dion (1991). The difficulties faced by Chinese students include parental pressure to achieve excellent academic achievements, racial discrimination, interracial dating, and maintenance of Chinese identity in an assimilationist, cultural environment (Dion \& Toner, 1988; Pak, Dion \& Dion, 1991). Similar findings are reported by Chataway and Berry (1989), as compared to their hostnational peers, Chinese student in Canada experienced higher trait anxiety, greater racial prejudice, and communication problems. Graham (1983) has reported the difficulties in cultural exclusion and communication with local Samoan students. It is found that while under the situation of unfamiliar foreign culture, Hong Kong Chinese students owe their academic excellence to the priority they give to school work rather than personal problems. A longitudinal study (Zheng $\&$ Berry, 1991), after repeated measurement of acculturative stress, reveals that Chinese sojourner students experience 
an increase in acculturative stress from pre-departure after three to four months post-arrival, before declining slowly for several years back to the pre-departure baseline.

\section{The Study}

\subsection{Subjects}

The subjects in the present study are 10 students enrolled in a doctoral program of a Hong Kong higher institution. All of them come from Mainland China, and have spent approximately 8 months in Hong Kong (with one or two exceptions). Their age ranges from 20 to 40. Most of them have jobs in higher institutions in Mainland China.

\subsection{Questionnaire}

The questionnaire consists of three parts: personal profile, acculturation index, and measurement of sociocultural adaptation. For personal profile, information on gender, age, months of having stayed in Hong Kong, times of visiting Hong Kong before the study experience, and the ability of speaking Cantonese would be collected. Researchers of previous studies have been interested in measuring a respondents' level of acculturation in a host society. The most frequent demographic indicators they use include "length of time in the country of residence, location and years of schooling, age at time of immigration..." (Dion \& Dion, 1996: 459). However, these indicators are not satisfactory enough to reflect individual differences. The above information is collected for the following reasons. First, gender is found related significantly to acculturation attitudes. It is reported that women are more assertive about their original culture and slower than men in accepting the host culture (Ouarasse, and Vijver, 2005). Age range of the subjects is mostly between 30-40, with one or two exceptions. Several demographic questions like, "Months of staying in Hong Kong", and "times visiting Hong Kong", "ability of speaking Cantonese" are included to identify whether these two factors affect acculturation attitudes and sociocultural adaptation.

The second part of the questionnaire is the acculturation index (cf. Ward, \& Rana-Deuba, 1999). 21 cognitive and behavioral questions including aspects in clothing, pace of life, food, religious beliefs, material comfort, self-identify, accommodation, values, friendships, family life, etc. are included. It is a 7-point scale rating, enquiring the subjects to indicate the similarity between their own life experience and those of their co-nationals and again with the hostnationals. If the life experiences of subjects are similar to both co-nationals and host-nationals, integration strategy is used; if similar to only co-nationals, or host-nationals, separation or assimilation strategy is used; if similar to neither group, separation strategy is used. The 6 items from the original 21-item questionnaire are deleted, including family life, accommodation/residence, perceptions of co-nationals, perceptions of host nationals, worldview, and employment activities. Two reasons are involved in doing this. One is to shorten the list, the other is to deduct those irrelevant to the subjects' experiences like family life, employment activities, or items that are too abstract like world view, perceptions of co-nationals, perceptions of host nationals. The score of the index ranges from 15-105.

The final part of the questionnaire is the measurement of sociocultural adaptation, which is a revised version of the Sociocultural Adaptation Scale devised by Ward \& Kennedy (1999). The original scale is made up of 41 items of social situations, and requires respondents to indicate the degree of difficulty they encounter in those social situations, using a five-point scale (no difficulty / slight difficulty / moderate difficulty / great difficulty / extreme difficulty). The range of difficulty is from 0 to 84. Some adaptations have been made to the questionnaire to include fewer items, and to make it better organized. Altogether 4 sections (interpersonal relationship, public situations, academic situations, ideology domain) are made upon the original items. 20 items are deleted for reasons of irrelevance or unimportance. For example, "going to social events/gathering/functions", "worshiping in your own way", "relating to older people", "accepting/understanding the local political system", "understanding the locals' world view", etc. are deleted due to their irrelevance; meanwhile, items like "getting used to the pace of life", "following rules and regulations", "adapting to local accommodation", "dealing with the climate", "adapting to the local etiquette", etc. are deleted because of their unimportance.

\subsection{Results and Discussion}

The calculation of acculturation attitudes follows the method of Ward and Rana-Deuba (1999). 7 valid questionnaires are collected. Median scores are first obtained for co-nationals and host-nationals, which is 95 for co-nationals, and 49 for host-nationals. Subjects with a co-national acculturation score higher than 95 would be seen as valuing co-nationals identification, and those with a host-national score higher than 49 would be seen as valuing host-national identification. Then, among the 7 subjects, 2 cases of assimilation, 2 cases of integration, 2 cases of separation and 1 case of marginalization are found. Interestingly, the 2 cases of separation and 1 case of marginalization are exactly the two youngest and one oldest subjects in the group. Similar to the findings of Ouarasse, \& Vijver (2005), this may give some proof that age may be an influential factor in acculturation attitude. As for the gender factor, the two female subjects in the sample each feature integration and assimilation, with one young subject (aged between 20-30) having low conational identification, and high host-national identification. This is contradictory to the previous studies that women are more assertive to their own culture and slower in accepting the host-culture (Ouarasse, \& Vijver, 2005). But the limited sample size may to some extent affect the reliability of the result.

As to the sociocultural adaptation, 10 valid questionnaires are collected. The total degree of difficulties ranges from 7 to 40. The average scores for each section (interpersonal relationship, public situations, academic situations, ideology domain) are 14.6, 2.7, 1.9 and 4.5 respectively. The result indicates that most difficulties encountered by subjects occur in interpersonal domain, followed by the ideology domain, even fewer difficulties are met in the public situations, and the least are met in academic situations. It is reflected that the interpersonal relationship may be the area that is most 
influential to the sociocultural adaptation of the subjects. Also, since the subjects equally have high educational level (students of a doctoral program), it is no wonder that academic domain is the area that they meet with least amount of difficulties.

According to the profiles given by the subjects, 4 of them are capable of communicating in Cantonese. A comparison is thus to be made upon those who speak and do not speak Cantonese - the local language spoken in Hong Kong. In the domain of interpersonal relationship, those who can speak Cantonese have an average score of 26.2 in degrees of difficulties, while the average number for those who cannot speak Cantonese is 21.8. This contrast shows that language competence may not be the dominant factor in sociocultural adaptation. In terms of gender, the average score for female subjects is 20.2 while male subjects has an average score of 25.8 , which reflect the fact that female sojourners in Hong Kong are adapting better than their male peers. This finding does not conform to those of Ouarasse and Vijver (2005), who hold that women are slower in accepting the host culture.

\section{Conclusion}

The present study has found out that age and gender may influence acculturation strategies. The measurement of sociocultural adaptation shows that interpersonal relationship is the area that the subjects have the most difficulties with, while academic domain is the area with the least difficulties. Also, the results have shown that competence of local language is not a determinant factor of the sociocultural adaptation; while female subjects seem to adapt better than male subjects.

Due to the limited sample size, the study is very primitive in nature. Further research involving larger number of subjects is expected to be carried out so as to find out more about the influence of gender, age, education, and language on Chinese Mainland sojourners' acculturation strategy and sociocultural adaptation, as well as the relationship between the above two constructs.

\section{References}

Ataca, B., \& Berry, J. W. (2002). Psychological, sociocultural, and marital adaptation of Turkish immigrant couples in Canada. International Journal of Psychology, 37(1), 13-26.

Berry, J. W., Kim, U., Power, S., Young, M., \& Bujaki, M. (1989). Acculturation attitudes in plural societies. Applied Psychology, 38(2), 185-206.

Brisset, C., Safdar, S., Lewis, J. R., \& Sabatier, C. (2010). Psychological and sociocultural adaptation of university students in France: The case of Vietnamese international students. International Journal of Intercultural Relations, $34(4), 413-426$.

Chataway, C. J., \& Berry, J. W. (1989). Acculturation experiences, appraisal, coping and adaptation. Canadian Journal of Behavioral Science, 21, 295-309.

Dion, K. L., \& Dion, K. K. (1996). Chinese adaptation to foreign cultures. In M. H. Bond (Ed.), The Handbook of Chinese Psychology (pp.457-478). Oxford and New York: Oxford University Press.

Dion, K. L., \& Toner, B. B. (1988). Ethnic differences in test anxiety. The Journal of Social Psychology, 128(2), 165172.

Furnham, A. F., \& Bochner, S. (1982) Social difficulty in a foreign culture: An empirical analysis of culture shock. In Bochner, S. (Ed.) Culture in contact: Studies in cross cultural interaction (pp. 161-198). Oxford: Oxford University Press.

Graham, M. A. (1983). Acculturative stress among Polynesian, Asian and American students on the Brigham Young University-Hawaii campus. International Journal of Intercultural Relations, 7, 79-103.

Guo, S. S. (2014). Xiangjiang Maibo-Neidisheng "Gangpiao" zhikun. Retrieved from http://www.hkpecs.org/eNewsDetail.asp?enews_id=731.

Ip, M., \& Pang, D. (2005). New Zealand Chinese identity: Sojourners, model minority and multiple identities. In Liu, J. H., McCreanor,T., McIntosh, T., \& Teaiwa, T. (Eds.), New Zealand identities: Departures and destinations (pp. 174190). Wellington: Victoria University Press.

Jasinskaja-Lahti, I., \& Liebkind, K. (2000). Predictors of the actual degree of acculturation of Russian-speaking immigrant adolescents in Finland. International Journal of Intercultural Relations, 24(4), 503-518.

Klemens, M. J., \& Bikos, L. H. (2009). Psychological well-being and sociocultural adaptation in college-aged, repatriated, missionary kids. Mental Health, Religion and Culture, 12(7), 721-733.

Leung, C. (2001). The sociocultural and psychological adaptation of Chinese migrant adolescents in Australia and Canada. International Journal of Psychology, 36(1), 8-19.

Ouarasse, O. A., \& Vijver, F. J. van de (2005). The role of demographic variables and acculturation attitudes in predicting sociocultural and psychological adaptation in Moroccans in the Netherlands. International Journal of Intercultural Relations, 29(3), 251-272.

Pak, A. W. P., Dion, K. L., \& Dion, K. K. (1991). Social-psychological correlates of experienced discrimination: Test of the double jeopardy hypothesis. International Journal of Intercultural Relations, 15(2), 243-253. 
Redfield, R., Linton, R., \& Herskovits, M. J. (1936). Memorandum on the study of acculturation. American Anthropologist, 38, 149-152.

Searle, W. \& Ward, C. (1990). The prediction of psychological and sociocultural adjustment during cross-cultural transitions. International Journal of Intercultural Relations, 14, 449-464.

Shibutani, T. \& Kwan, K. (1965). Ethnic stratification: A comparative approach. New York: Macmillan.

Sochos, A., \& Diniz, M. (2012). The role of attachment in immigrant sociocultural adaptation and psychological distress. Journal of Community \& Applied Social Psychology, 22(1), 75-91.

Virta, E., Sam, D. L., \& Westin, C. (2004). Adolescents with Turkish background in Norway and Sweden: A comparative study of their psychological adaptation. Scandinavian Journal of Psychology, 45(1), 15-25.

Ward, C., \& Kennedy, A. (1994). Acculturation strategies, psychological adjustment and sociocultural competence during cross-cultural transitions. International Journal of Intercultural Relations, 18, 329-343.

Ward, C., \& Kennedy, A. (1999). The measurement of sociocultural adaptation. International Journal of Intercultural Relations, 23(4), 659-677.

Ward, C., \& Rana-Deuba, R. (1999). Acculturation and adaptation revisited. Journal of Cross-cultural Psychology, 30, $422-442$

Wiseman, R. L. (Ed.). (1995). Intercultural communication theory. California: Sage.

Zheng, X., \& Berry, J. W. (1991). Psychological adaptation of Chinese sojourners in Canada. International Journal of Psychology, 26(4), 451-470. 